\title{
Use of levocetrizine in the management of type IV hypersensitivity to lidocaine: a case report
}

\author{
Mansi Dey ${ }^{1 *}$, Bibhu Prasad Mishra ${ }^{2}$, Abhijeeta Sahoo
}

\author{
${ }^{1}$ Dey's Multispeciality Dental Clinic and Oral Surgery Centre, Dehradun, Uttarakhand, India \\ ${ }^{2} \mathrm{Hi}-\mathrm{Tech}$ Dental College and Hospital, Odisa, India
}

Received: 25 October 2021

Accepted: 12 November 2021

\section{*Correspondence:}

Dr. Mansi Dey,

Email: shikhadey2904@gmail.com

Copyright: (c) the author(s), publisher and licensee Medip Academy. This is an open-access article distributed under the terms of the Creative Commons Attribution Non-Commercial License, which permits unrestricted non-commercial use, distribution, and reproduction in any medium, provided the original work is properly cited.

\begin{abstract}
Lidocaine is a commonly used local anesthetic in the field of dentistry. It has been known to cause allergic reactions, mainly immunoglobulin (IgE)-mediated and T-cell -mediated type IV reactions, which require the use of alternative drugs without adverse effects. Here we present the case of a 29 year old female patient who developed Type IV hypersensitivity reaction in the vicinity of the injection site after the administration of lidocaine local anesthetic for performing exodontia. Levocetrizine tablet was prescribed in order to relieve the symptoms of the reaction. Levocetrizine is a selective, potent, oral histamine $\mathrm{H}(1)$ receptor antagonist that is used for the symptomatic treatment of allergic rhinitis and chronic idiopathic urticaria. It has been reported to be effective and generally well tolerated by the patients. In our case also it was able to cure Type IV hypersensitivity reaction to lidocaine without producing any adverse events. Apart from curing allergic rhinitis and urticaria, levocetrizine is a wonderful option for treating Type IV hypersensitivity reaction to a local anesthetic, and it hardly produces any adverse effect. More cases are required to be reported in the future in order to support this article.
\end{abstract}

Keywords: Lidocaine, Allergy, Levocetrizine

\section{INTRODUCTION}

Lidocaine is a drug that is commonly used as a local anesthetic in dentistry. Though a useful local anesthetic, it has been known to cause allergies or other adverse effects that may range from mild symptoms, such as urticaria, erythema, and intense itching to severe reactions in the form of angioedema and/or respiratory distress or even more severe life-threatening anaphylactic responses include symptoms of apnea, hypotension, and loss of consciousness. ${ }^{1-4}$

Allergic reactions to local anesthetics are known to involve two types of reactions namely immunoglobulin E (IgE)-mediated type I and T-cell-mediated type IV reactions.4 In cases of suspected allergy to lidocaine, patients should be tested using other local anesthetics, so that the one without any adverse effects can be chosen. In case any local anesthetic without adverse effects is not available, dental treatment can be performed under general anesthesia. ${ }^{4} 1 \%$ diphenhydramine is a safe and inexpensive method in patients who are allergic to local anesthesics. $^{5}$

In this article, we report a case of type IV hypersensitivity reaction to lidocaine, which was successfully treated using an antihistamine called as levocterizin.

\section{CASE REPORT}

A 29 year old female patient reported to our clinic with a complaint of pain in the upper left region of the mouth. 
The patient did not have any history of any systemic illness, nor was she pregnant or a lactating mother. She had a history of dental extraction two years back. However, she could not recall any allergic reaction. On intraoral examination we found a grossly decayed upper left third molar with dislodged restoration. Half the occlusal portion and almost the whole buccal portion of the tooth were missing. Caries had destroyed the tooth to such an extent that the pulp chamber was also exposed. Also, the tooth was tender on percussion. After taking the radiograph, the tooth was extracted under local anesthesia using lidocaine, with the help of forceps and elevators.

Two days after the extraction the patient came with a complaint of severe itching in the injection sites. Though the pain had subsided, the patient reported that itching had started one day after the extraction of tooth was performed and that on the second day it had increased to such an extent that she could not even sleep. On examination we could find an erythematous area adjacent to the left maxillary molars (Figure 1). This was the type IV hypersensitivity reaction in the form of contact allergy that had occurred in the vicinity of injection site of posterior superior alveolar nerve block. The patient also reported of itching in the injection site on the palatal area (where greater palatine nerve block was injected), but that was not as severe as that which had occurred on the buccal aspect.

She was prescribed a tablet Xevor (contains $5 \mathrm{mg}$ levocetrizine hydrochloride) once a day for 3 days. The patient reported of getting relieve from severe itching after taking a single dose of this medicine. Hence, she was asked to discontinue the further use. Nevertheless, she did not report any symptomonce a day for 3 days. The patient reported of getting relieve from severe itching after taking a single dose of this medicine. Hence, she was asked to discontinue the further use. Nevertheless, she did not report any symptom.

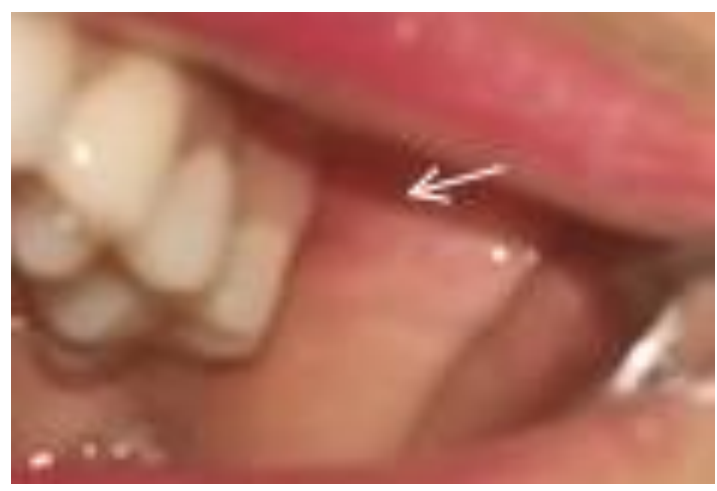

Figure 1: Contact allergy as a result of type IV hypersensitivity to lidocaine.

\section{DISCUSSION}

Contact allergy to oral mucosa can be caused by dental materials, food and oral hygiene products. 6 It can also be caused by local anesthetics. Although it is commonly caused by esther-type local anesthetics, delayed hypersensitivity due to amide-type local anesthetics has been found to be rare. ${ }^{7}$ Here we present the case of a type IV hypersensitivity to lidocaine that presented as contact allergy in the vicinity of injection site for extraction of left maxillary third molar, and was successfully treated by a single dose of $5 \mathrm{mg}$ levocetrizine hydrochloride.

In suspected cases of lidocaine contact type IV sensitivity, patients should be patch tested to the drug. If positive patch test reactions occur, they should be confirmed by intradermal testing with lidocaine. Patch testing should also be performed with other injectable anesthetics in order to provide the patient with alternative local anesthetics, and followed by intradermal testing if positive patch test reactions are found. ${ }^{8}$ However, in our case the same was not be done as the patient could not recall any allergic reaction to the local anesthetic after extraction of her tooth that was performed 2 years back. When the patient was diagnosed with type IV hypersensitivity to lidocaine, she was prescribed a tablet 5 mg levocetrizine hydrochloride (Xevor) and got cured by the single dose.

Levocetirizine is a selective, potent, oral histamine $\mathrm{H}(1)$ receptor antagonist that is used for the symptomatic treatment of allergic rhinitis and chronic idiopathic urticaria. It has been reported to be effective and generally well tolerated by the patients. It has a rapid onset and long duration of antihistaminic effect Other advantages include rapid absorption, high bioavailability, a low potential for drug interactions, low volume of distribution and a lack of effect on cognition, psychomotor function and the cardiovascular system. ${ }^{9}$

As far as side effects are concerned, results have demonstrated that a single dose or repeated doses of levocetirizine have no modification on memory. On the other hand, diphenhydramine has shown to induce a significant reduction in attention and motor skills as early as after the first dose. ${ }^{10}$

Potter has reported the absence of significant adverse reactions during a six-week treatment with levocetirizine at $5 \mathrm{mg} /$ day. The most frequent adverse reaction reported was headache $(34.7 \%)$, influenza-like symptoms (16.7\%), high respiratory tract infections $(6.7 \%)$ and drowsiness $(6.0 \%)$. One of the subjects had an increase in alanine aminotransferase, correlated with the drug, which regressed spontaneously after nine days. No cases of increased electrocardiogram (ECG) QT interval were found. ${ }^{11}$ Cardiotoxic effects have been found to be absent. $^{12}$

In accordance with these studies, our case also did not report any adverse effect with the use of levocetrizine in the treatment of Type IV hypersensitivity reaction to lidocaine. However, only a single dose of $5 \mathrm{mg}$ levocetrizine was used. 


\section{CONCLUSION}

Apart from curing allergic rhinitis and urticaria, levocetrizine is a wonderful option for treating Type IV hypersensitivity reaction to a local anesthetic. As low as a single dose of $5 \mathrm{mg}$ levocetrizine can turn up to be efficient in the management of the same, and it hardly produces any adverse effect. More cases are required to be reported in the future in order to support this article.

Funding: No funding sources Conflict of interest: None declared

Ethical approval: Not required

\section{REFERENCES}

1. Batinac T, Sotošek Tokmadžić V, Peharda V, Brajac I. Adverse reactions and alleged allergy to local anesthetics: analysis of 331 patients. J Dermatol. 2013;40(7):522-7.

2. Finder RL, Moore PA. Adverse drug reactions to local anesthesia. Dent Clin. 2002;46(4):747-57.

3. Speca SJ, Boynes SG, Cuddy MA. Allergic reactions to local anesthetic formulations. Dental Clinics of North America. 2010;54(4):655-64.

4. Lee J, Lee JY, Kim HJ, Seo KS. Dental anesthesia for patients with allergic reactions to lidocaine: two case reports. J Dent Anesthesia Pain Med. 2016;16(3):209-12.

5. Dey M, Mishra BP, Awasthi D, Sahoo A. Articaine as an alternative in lidocaine allergy: Case report of a seventy year old male patient. Int J Surg Case Reports. 2020;77:941-3.
6. Minciullo PL, Paolino G, Vacca M, Gangemi S, Nettis E. Unmet diagnostic needs in contact oral mucosal allergies. Clin Molecular Allergy. 2016;14(1):1-8.

7. Estrada-Rodriguez JL, Rodríguez-Paredes A, Latasa M, Perez-Laiz JL. Delayed hypersensitivity to lidocaine cross-reactivity with others amide-type anesthetics. Int J Aller Medcations. 2015;1(007).

8. Mackley CL, Marks JG, Anderson BE. Delayed-type hypersensitivity to lidocaine. Arch Dermatol. 2003;139(3):343-6.

9. Hair PI, Scott LJ. Levocetirizine. Drugs. 2006;66(7):973-96.

10. Tillement JP. A low distribution volume as a determinant of efficacy and safety for histamine (H1 antagonists. Allergy. 1995;50:12-6.

11. Potter PC, Study Group. Levocetirizine is effective for symptom relief including nasal congestion in adolescent and adult (PAR) sensitized to house dust mites. Allergy. 2003;58(9):893-9.

12. Hulhoven R, Rosillon D, Letiexhe M, Meeus MA, Daoust A, Stockis A. Levocetirizine does not prolong the QT/QTc interval in healthy subjects: results from a thorough QT study. Euro J Clin Pharmacol. 2007;63(11):1011-7.

Cite this article as: Dey M, Mishra BP, Sahoo A. Use of levocetrizine in the management of type IV hypersensitivity to lidocaine: a case report. Int $\mathbf{J}$ Basic Clin Pharmacol 2021;10:1424-6. 